\title{
Aeromonas spp. E Plesiomonas shigelloides ISOLADAS A PARTIR DE MEXILHÕES (Perna perna) IN NATURA E PRÉ-COZIDOS NO RIO DE JANEIRO, RJ ${ }^{1}$
}

\author{
Christiane Soares PEREIRA',*, Cristina de Albuquerque POSSAS ${ }^{3}$, \\ Celio Mauro VIANA ${ }^{4}$, Dalia dos Prazeres RODRIGUES ${ }^{5}$
}

\section{RESUMO}

O ecossistema aquático é o habitat de mexilhões (Perna perna), animais filtradores que refletem a qualidade ambiental através de análise microbiológica de sua carne. No presente trabalho avaliou-se a presença de patógenos emergentes (Aeromonas hydrophila e Plesiomonas shigelloides), em mexilhões in natura e pré-cozidos coletados por pescadores da Estação Experimental de Cultivo de Mexilhões situada em Jurujuba, Niterói, Rio de Janeiro. Foram analisadas 86 amostras de mexilhões (43 in natura e 43 pré-cozidos) as quais foram submetidas a enriquecimento em Água Peptonada Alcalina (APA) acrescida de 1 e 3\% de Cloreto de Sódio (NaCl) e em solução Salina de Butterfield, incubadas a $37^{\circ} \mathrm{C}$ por 24 horas. Em seguida, foram semeadas em Ágar Seletivo para PseudomonasAeromonas (GSP), Ágar Tiossulfato Citrato Bile Sacarose (TCBS) e Ágar Inositol Bile Verde Brilhante (IBB). A análise geral dos resultados permitiu a identificação de Areomonas spp e Plesiomonas shigelloides em $86 \%$ das amostras de mexilhões in natura e pré-cozidas avaliadas. A posterior caracterização bioquímica permitiu a identificação das espécies Aeromonas media (37,10\%), A. hydrophila (15,50\%), A. caviae (14,80\%), A. veronii biogrupo veronii (11,60\%), Aeromonas sp. (7,36\%), A. sobria $(4,20 \%)$, A. trota $(4,20 \%)$, A. schubertii $(1,31 \%)$, A. jandaei $(1,31 \%)$, A. veronii biogrupo sobria $(0,52 \%)$ e Plesiomonas shigelloides $(2,10 \%)$. A relevância epidemiológica desses microrganismos em casos de gastrenterite humana, após consumo de mexilhões crus ou parcialmente cozidos, revela a importância de alertar as autoridades de Saúde Pública no Brasil, sobre a presença desses patógenos na cadeia alimentar e seus riscos para a saúde humana. Palavras-chave: Aeromonas spp.; Plesiomonas shigelloides; mexilhões; Saúde Pública.

\section{SUMMARY}

Aeromonas spp. AND Plesiomonas shigelloides ISOLATED FROM IN NATURA AND PRECOOKED MUSSELS (Perna perna) IN RIO DE JANEIRO, RJ, BRAZIL. The aquatic ecosystem is the habitat of mussels, filtrating animals that reflect the ambient quality through microbiological analysis. In the present investigation, we evaluated the presence of emergent pathogens (Aeromonas hydrophila and Plesiomonas shigelloides) from in natura and pre-cooked mussels collected by workers at the Experimental Station Mussels Cultive situated in Jurujuba, Niteroi, Rio de Janeiro. A total of 86 mussels (43 each in natura and precooked) were analyzed and the samples were submitted to enrichment in Alkaline Peptone Water (APW) added of 1 and 3\% Sodium Chloride (NaCl) and Butterfield's Saline incubated at $37^{\circ} \mathrm{C}$ for 24 hours. After, the samples were streaked onto Pseudomonas-Aeromonas Selective Agar (GSP), Thiossulfate Citrate Bile Sucrose Agar (TCBS) and Inositol Brilliant Green Bile Salts Agar (IBB). Aeromonas spp and Plesiomonas shigelloides were isolated from $86 \%$ in natura and precooked mussels avaliated. The biochemical characterization showed strains of Aeromonas media (37.10\%), A. hydrophila (15.50\%), A. caviae (14.80\%), A. veronii biogroupe veronii (11.60\%), Aeromonas sp. (7.36\%), A. sobria (4.20\%), A. trota (4.20\%), A. schubertii (1.31\%), A. jandaei (1.31\%), A. veronii biogroupe sobria $(0.52 \%)$, and Plesiomonas shigelloides $(2.10 \%)$. The epidemiological relevance of these microorganisms in cases of human gastroenteritis after mussels consumption without fully cooking reveal the importance to alert the Brazilian health authorities on the presence of these pathogens in food chain and the risks for human health.

Keywords: Aeromonas spp.; Plesiomonas shigelloides; mussels; Public Health.

\section{1 - INTRODUÇÃO}

O ecossistema aquático representa uma fonte de recursos naturais, favorecendo o cultivo de mexilhões, animais micrófagos que se alimentam de partículas e microrganismos em suspensão na água. O nível de absorção de nutrientes depende da temperatura, salinidade e salubridade do meio ambiente de cultivo ou extração dos mexilhões. Dessa forma, seu consumo pode

\footnotetext{
Recebido para publicação em 06/01/2003. Aceito para publicação em 18/08/2004 (001038).

2. Avenida Nossa Senhora de Fátima, 74 apto. 101 - Centro- CEP: 20240 051. E-mail: csoarespereira@hotmail.com Tel: (21) 22321638 / 91124145. 3. Escola Nacional de Saúde Pública, FIOCRUZ, Av Leopoldo Bulhões, 1480, CEP: 21041-210.

4. Departamento de Microbiologia de Alimentos, Faculdade de Veterinária, Universidade Federal Fluminense, Rua Vital Brasil Filho s/n, Santa Rosa, Niterói. CEP: 24020-091.

5. Departamento de Bacteriologia, IOC, FIOCRUZ, Av. Brasil, 4365, $3^{\circ}$ andar, Pav. Rocha Lima, cep: 21045-900.

* A quem a correspondência deve ser enviada.
}

representar risco para o homem quando oriundos de áreas poluídas ou contaminadas [15].

O gênero Aeromonas e a espécie Plesiomonas shigelloides são microrganismos de habitat predominantemente hídrico, pertencentes às famílias Aeromonadaceae e Vibrionaceae [9]. Sua freqüência de isolamento é mais elevada nos meses de verão, tanto nas zonas temperadas como nas tropicais [1].

Em nosso país, diversos estudos revelaram a incidência de Aeromonas spp. no ambiente aquático [11], em amostras de solo de jardim e áreas de recreação [14], a partir de pescado [2, 13], e vegetais [12]. Por outro lado, Plesiomonas shigelloides foi isolada em menores proporções, em nosso meio, a partir de pescado [8].

Aeromonas spp. e Plesiomonas shigelloides podem causar infecções entéricas ou extraintestinais após o consumo de água ou alimentos contaminados. As principais características das infecções causadas por essas bactérias são: diarréia aguda, especialmente em crianças e idosos, alguns casos de celulite ou infecção de feridas em manipuladores de alimentos ou profis- 
sionais de sistemas de aqüicultura [10]. Indivíduos imunodeprimidos ou portadores de distúrbios hepatobiliares podem sofrer complicações como septicemia e óbito. Contudo, a maioria dos casos em indivíduos saudáveis possui evolução autolimitada. O tratamento da infecção é baseado na reparação hidroeletrolítica e a antibioticoterapia recomendada somente em casos mais severos [16].

Pelo exposto, é possivel reconhecer a importância desses microrganismos para a Saúde Pública com relação ao consumo de mexilhões. O objetivo desta investigação foi avaliar a presença de Aeromonas hydrophila e Plesiomonas shigelloides em mexilhões in natura e précozidos coletados de uma estação experimental de cultivo no Rio de Janeiro.

\section{2 - MATERIAL E MÉTODOS}

Foram realizadas coletas quinzenais de mexilhões (Perna perna), e analisadas um total de 86 amostras, sendo 43 in natura (animal íntegro no interior valvar) e 43 pré-cozidas (submetidos a processo de aquecimento em vapor d'água por aproximadamente 3 minutos para retirada das valvas e subseqüente comercialização da parte comestível), no período de janeiro a dezembro de 2000. Os mexilhões foram coletados por pescadores da estação experimental de cultivo situada em Jurujuba no município de Niterói (RJ). As amostras, segundo informações dos pescadores, foram coletadas a partir de 19 pontos diferentes da região da Baía de Guanabara, assim denominados: Ilha dos Pais, Ilha Redonda, Ilha dos Veados, Ilha Palmeiras, Ilha Cagarras, Ilha Comprida, Ilha dos Cargos, Ilha da Feiticeira, Ilha das Mães, Ilha do Meio, Costão de Niterói, Ilhota do Aeroporto Santos Dumont, Ilha do Governador, Fortaleza de Santa Cruz, Praia de Boa Viagem, Praia de Icaraí, Praia de Botafogo, Praia do Flamengo e Praia da Urca.

As amostras de mexilhões (in natura e pré-cozidos) foram devidamente acondicionadas em embalagem de polietileno a qual é utilizada para comercialização, identificadas e colocadas em caixa de isopor contendo gelo reciclável. Em seguida, foram remetidas ao Laboratório de Enterobactérias, Departamento de Bacteriologia, Instituto Oswaldo Cruz, FIOCRUZ, para realização das análises microbiológicas, dentro de um prazo que não ultrapassou duas horas.

O procedimento utilizado nos dois grupos de amostras esteve representado inicialmente pela pesagem de 25 gramas de amostras in natura e 25 gramas de amostras pré-cozidas, efetuando-se a seguir para cada uma delas diluição em solução salina de Butterfield (225mL) e homogeneização em Warning-Blender (1500rpm/1 minuto). Foi retirada uma alíquota de $1 \mathrm{~mL}$ dessa mistura a qual foi transferida para três tubos, um deles contendo Água Peptonada Alcalina (APA) acrescida de 1\% de Cloreto de Sódio ( $\mathrm{NaCl}$ ), APA com 3\% de $\mathrm{NaCl}$ e um último contendo Salina de Butterfield, incubados a $37^{\circ} \mathrm{C}$ por 24 horas. Após esse período, procedeu-se a semeadura nos seguintes meios seletivos diferenciais: Ágar
Seletivo para Pseudomonas-Aeromonas -GSP, Ágar Tiossulfato Citrato Bile Sacarose -TCBS e Ágar Inositol Bile Verde Brilhante -IBB $\left(37^{\circ} \mathrm{C}-18\right.$ a $\left.24 \mathrm{~h}\right)$. As colônias suspeitas (5 a 10) foram repicadas para meios de triagem (Kligler Iron Agar e Lysine Iron Agar) e ágar nutriente acrescido de $1 \%$ de $\mathrm{NaCl}$. Após a seleção das cepas citocromo-oxidase positivas, foram realizados testes bioquímicos, baseados na resistência ao agente vibriostático O/129, fermentação de carboidratos e descarboxilação de aminoácidos, a fim de obter a caracterização das espécies de microrganismos isolados [4].

\section{3 - RESULTADOS E DISCUSSÃO}

Do total geral de 86 amostras de mexilhões (Perna perna) analisados, a presença de Aeromonas spp e Plesiomonas shigelloides foi detectada em 74 (86\%) das amostras in natura e pré-cozidas. Considerando as duas amostragens utilizadas no presente estudo, foram isoladas 380 cepas de Aeromonas spp. e Plesiomonas shigelloides $(54,20 \%$ pré-cozidas e $45,80 \%$ in natura). Por outro lado, um percentual de $14 \%$ dos mexilhões analisados não apresentou isolamento de nenhum dos gêneros analisadsos.

A caracterização bioquímica permitiu a identificação de 372 cepas em nove espécies de Aeromonas spp., distribuídas de acordo com a freqüência: Aeromonas media (37,10\%), A. hydrophila (15,50\%), A. caviae (14,80\%), A. veronii biogrupo veronii (11,60\%), A. sobria (4,20\%), A. trota (4,20\%), A. schubertii (1,31\%), A. jandaei (1,31\%), Aeromonas veronii biogrupo sobria (0,52\%) e 7,36\% cepas caracterizadas como Aeromonas sp., Com relação a Plesiomonas shigelloides foram isoladas 8 cepas, sendo $1,57 \%$ a partir dos mexilhões pré-cozidos e $0,52 \%$ oriundas das amostras in natura (Tabela 1).

Nos mexilhões in natura, as espécies mais freqüentes foram: Aeromonas media (12,36\%), A. hydrophila (10\%), A. veronii biogrupo veronii $(7,10 \%)$, A. caviae $(5,80 \%)$, Aeromonas sp. (4,73\%), A. trota (2,63\%), A. sobria (2,40\%) e $A$. veronii biogrupo sobria $(0,26 \%)$. Nos mexilhões submetidos ao processo de pré-cocção as espécies mais isoladas foram: Aeromonas media (24,73\%), A. caviae (9\%), A. hydrophila (5,50\%), A. veronii biogrupo veronii $(4,47 \%)$, Aeromonas sp. (2,63\%), A. sobria (1,84\%), A. trota (1,57\%) e A. veronii biogrupo sobria $(0,26 \%)$. Ressalta-se que a presença de Aeromonas schubertii e A.jandaei foi verificada apenas a partir das amostras pré-cozidas representando, ambas, uma freqüência de isolamento de 1,31\%.

Avaliando os dados da presente investigação referentes ao período, número de amostras analisadas e microrganismos isolados, verificamos que os meses de agosto e outubro apresentaram maiores freqüências de A. media, A. hydrophila, A. caviae e A. veronii biogupo veronii. Com relação a Plesiomonas shigelloides, observamos seu isolamento de forma esporádica nos meses de março, junho, setembro e outubro (Tabela 2).

No que se refere aos locais de coleta foi possível observar que a espécie Aeromonas hydrophila estava no momento do estudo amplamente distribuída no ecos- 
sistema aquático, tendo sido isolada dos 19 pontos de coleta avaliados. Espécies como Aeromonas media, A. veronii biogrupo veronii e $A$. caviae também foram isoladas com freqüência a partir de mexilhões oriundos locais estudados. Cabe ressaltar que mexilhões coletados de pontos como Ilha do Governador, Praia de Boa Viagem e Praia do Flamengo apresentaram um número total de cepas bastante significativo (Tabela 3).

TABELA 1. Freqüência das cepas de Aeromonas spp. e $P$. shigelloides isoladas a partir de mexilhões in natura $\mathrm{e}$ pré-cozidos comercializados pela EECM.

\begin{tabular}{|c|c|c|c|}
\hline \multirow[b]{2}{*}{$\begin{array}{l}\text { Microrganismos } \\
\text { Isolados }\end{array}$} & \multicolumn{2}{|c|}{ Mexilhões } & \multirow[b]{2}{*}{$\begin{array}{c}\text { Total de Cepas } \\
\text { Caracterizadas } \\
\text { N (\%) }\end{array}$} \\
\hline & $\begin{array}{c}\text { in natura } \\
\mathrm{N}(\%)\end{array}$ & $\begin{array}{l}\text { Pré-cozidos } \\
\text { N (\%) }\end{array}$ & \\
\hline A. media & $47(12,36)$ & $94(24,73)$ & $141(37,10)$ \\
\hline A. hydrophila & $38(10,00)$ & $21(5,50)$ & $59(15,50)$ \\
\hline A. caviae & $22(5,80)$ & $34(9,00)$ & $56(14,80)$ \\
\hline A. veronii veronii & $27(7,10)$ & $17(4,47)$ & $44(11,60)$ \\
\hline Aeromonas sp. & $18(4,73)$ & $10(2,63)$ & $28(7,36)$ \\
\hline A. sóbria & $09(2,40)$ & $07(1,84)$ & $16(4,20)$ \\
\hline A. trota & $10(2,63)$ & $06(1,57)$ & $16(4,20)$ \\
\hline P. shigelloides & $02(0,52)$ & $06(1,57)$ & $08(2,10)$ \\
\hline A. veronii sóbria & $01(0,26)$ & $01 \quad(0,26)$ & $02(0,52)$ \\
\hline A. schubertii & - & $05(1,31)$ & $05(1,31)$ \\
\hline A. jandaei & - & $05(1,31)$ & $05(1,31)$ \\
\hline Total & $174(45,8)$ & $206(54,20)$ & $380(100)$ \\
\hline
\end{tabular}

TABELA 2. Distribuição das cepas de Aeromonas spp. e Plesiomonas shigelloides detectadas em mexilhões (Perna perna) in natura e pré-cozidos, de acordo com o período de coleta.

\begin{tabular}{|c|c|c|c|c|c|c|c|c|c|c|c|c|c|}
\hline Mês & $\begin{array}{c}\text { Coletas } \\
\left(\mathrm{N}^{*}\right)\end{array}$ & $\begin{array}{l}\frac{\pi}{2} \\
\frac{1}{2} \\
\frac{0}{0} \\
\stackrel{2}{\sigma}\end{array}$ & $\begin{array}{l}\cdot \frac{\pi}{2} \\
\frac{0}{0} \\
\infty \\
\leftarrow\end{array}$ & 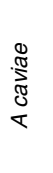 & $\begin{array}{l}\frac{\pi}{\delta} \\
\mathbb{8} \\
\varepsilon \\
\tau\end{array}$ & 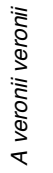 & 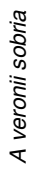 & $\frac{\pi}{0}$ & 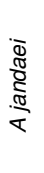 & 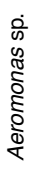 & 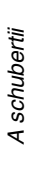 & 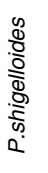 & $\begin{array}{l}\text { Total } \\
\text { cepas }\end{array}$ \\
\hline Janeiro & 3 & 1 & 2 & 4 & 1 & 0 & 1 & 3 & 0 & 0 & 0 & 0 & 12 \\
\hline Fevereiro & 3 & 3 & 3 & 3 & 10 & 2 & 0 & 2 & 0 & 0 & 0 & 0 & 23 \\
\hline Março & 4 & 0 & 1 & 0 & 4 & 1 & 0 & 0 & 0 & 2 & 0 & 3 & 11 \\
\hline Abril & 2 & 0 & 2 & 4 & 0 & 2 & 0 & 1 & 3 & 0 & 4 & 0 & 16 \\
\hline Maio & 2 & 0 & 0 & 0 & 2 & 0 & 1 & 0 & 0 & 0 & 1 & 0 & 04 \\
\hline Junho & 4 & 4 & 7 & 8 & 13 & 1 & 0 & 2 & 0 & 0 & 0 & 2 & 37 \\
\hline Julho & 4 & 3 & 0 & 2 & 16 & 16 & 0 & 0 & 0 & 6 & 0 & 0 & 43 \\
\hline Agosto & 2 & 29 & 1 & 19 & 30 & 9 & 0 & 5 & 0 & 7 & 0 & 0 & 100 \\
\hline Setembro & 6 & 4 & 0 & 5 & 9 & 7 & 0 & 1 & 0 & 7 & 0 & 2 & 35 \\
\hline Outubro & 2 & 4 & 0 & 3 & 30 & 3 & 0 & 2 & 1 & 2 & 0 & 1 & 46 \\
\hline Novembro & 7 & 5 & 0 & 0 & 12 & 1 & 0 & 0 & 0 & 2 & 0 & 0 & 20 \\
\hline Dezembro & 4 & 6 & 0 & 8 & 14 & 2 & 0 & 0 & 1 & 2 & 0 & 0 & 33 \\
\hline
\end{tabular}

*N= número de coletas realizadas durante a pesquisa.
TABELA 3. Distribuição das cepas de Aeromonas spp. e Plesiomonas shigelloides isoladas de mexilhões (Perna perna) in natura e pré-cozidos, de acordo com o local de coleta.

\begin{tabular}{|c|c|c|c|c|c|c|c|c|c|c|c|c|}
\hline \multirow[b]{2}{*}{ Locais de Coleta } & \multicolumn{11}{|c|}{ Cepas isoladas } & \multirow[b]{2}{*}{$\begin{array}{l}\text { Total } \\
\text { de } \\
\text { cepas } \\
\text { por } \\
\text { locali- } \\
\text { dade }\end{array}$} \\
\hline & $\begin{array}{l}\frac{\pi}{\delta} \\
\tilde{E} \\
\varepsilon \\
\alpha\end{array}$ & 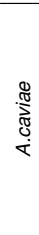 & $\begin{array}{l}\frac{\pi}{2} \\
\frac{2}{2} \\
\frac{2}{2} \\
\frac{1}{2} \\
\dot{2}\end{array}$ & 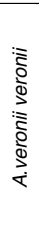 & 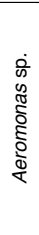 & 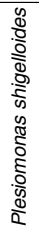 & 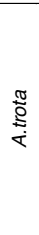 & 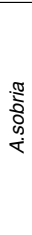 & 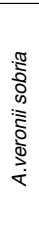 & 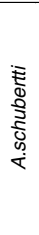 & 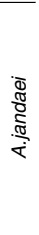 & \\
\hline Ilha dos Pais & 7 & 1 & 1 & 1 & 3 & - & - & - & - & - & - & 13 \\
\hline Ilha Redonda & - & 3 & 1 & - & 1 & - & - & - & - & - & - & 5 \\
\hline Ilha dos Veados & 10 & - & 1 & 2 & 1 & - & - & 1 & - & - & - & 15 \\
\hline Ilha Palmeiras & 10 & 3 & 5 & 2 & 1 & - & - & - & - & - & - & 21 \\
\hline Ilha Cagarras & 5 & 2 & 5 & 2 & 3 & - & - & - & - & - & 1 & 18 \\
\hline Ilha Comprida & 1 & 3 & 1 & 2 & - & - & - & 1 & - & - & - & 8 \\
\hline Ilha dos Cargos & 9 & 2 & 2 & 2 & 2 & 2 & 1 & 2 & - & - & - & 22 \\
\hline Ilha da Feiticeira & 10 & - & 8 & 2 & - & - & 1 & 1 & - & - & - & 22 \\
\hline Ilha das Mães & 12 & 2 & 1 & 1 & - & - & 1 & 1 & - & - & - & 18 \\
\hline Ilha do Meio & 3 & - & 3 & 3 & 2 & 1 & 1 & - & - & - & - & 14 \\
\hline Costão de Niterói & 3 & 7 & 1 & 2 & 2 & 1 & 1 & 1 & - & - & - & 18 \\
\hline Ilhota do Aeroporto Santos Dumont & 8 & 5 & 4 & 2 & 2 & - & 1 & 1 & 2 & 1 & - & 26 \\
\hline Ilha do Governador & 23 & 5 & 1 & 3 & - & - & 2 & - & - & 4 & 3 & 41 \\
\hline Fortaleza de Santa Cruz & 4 & 3 & 2 & 2 & 7 & - & 1 & 1 & - & - & - & 20 \\
\hline Praia de Boa Viagem & 9 & 4 & 7 & 5 & 1 & 2 & 1 & 1 & - & - & - & 30 \\
\hline Praia de Icaraí & 10 & 5 & 1 & 2 & 1 & 2 & 1 & 2 & - & - & - & 24 \\
\hline Praia de Botafogo & 5 & 1 & 5 & 8 & 1 & - & 2 & 2 & - & - & - & 24 \\
\hline Praia do Flamengo & 11 & 4 & 8 & 1 & 1 & - & 2 & 1 & - & - & - & 28 \\
\hline Praia da Urca & 1 & 6 & 2 & 2 & - & - & 1 & 1 & - & - & - & 13 \\
\hline Total de Cepas & 141 & 56 & 59 & 44 & 28 & 8 & 16 & 16 & 2 & 5 & 5 & 380 \\
\hline
\end{tabular}

No cômputo geral, os microrganismos mais incidentes foram Aeromonas media $(37,10 \%)$, A. hydrophila (15,50\%), A. caviae $(14,80 \%)$ e A. veronii biogrupo veronii $(11,60 \%)$, resultados estes que estão muito próximos daqueles observados por diversos autores [11, 13]. Tal fato revela a importância desses microrganismos para a Saúde Pública, tendo em vista seu elevado potencial patogênico para o ser humano.

Aeromonas media representou a espécie mais incidente tanto a partir das amostras de mexilhões in natura $(12,36 \%)$ quanto das pré-cozidas $(24,73 \%)$. Tais resultados podem ser considerados relevantes a partir do momento que este microrganismo não costuma ser referido com a freqüência na qual foi isolada nesta investigação. Outrossim, esses dados sugerem que o habitat destes mexilhões representava no período da investigação um importante reservatório natural de microrganismos dessa espécie [5].

Aeromonas hydrophila apresentou significativa percentagem de isolamento a partir das amostras in natura (10\%) e pré-cozidos (5,50\%). Considerando que tais microrganismos são capazes de produzir inúmeros produtos, incluindo toxinas e enzimas, os quais podem se 
manter nos alimentos mesmo em condição de refrigeração, os resultados obtidos alertam para a possibilidade de ocorrência de gastrenterite, bem como infecção cutânea em manipuladores de alimentos. Neste contexto, espécies como A. veronii biogrupo veronii $(7,10 \%)$ e A. caviae $(4,47 \%)$ isoladas de mexilhões in natura, também devem ser incluídas, pois causam diarréia aguda em crianças e idosos [16].

Por outro lado, observou-se uma menor freqüência de isolamento para as espécies Aeromonas sobria e A. trota a partir de mexilhões pré-cozidos. Considerando que A. sobria tem sido reportada como patógeno emergente isolada de fontes humanas e animais de suma importância monitorar sua presença em elimentos e avaliar seus riscos para a Saúde Pública [8, 13]. Em contrapartida a presença de A. trota assume especial importância para sistemas de aqüicultura de trutas e mexilhões, uma vez que este microrganismo está relacionado à ocorrência de epizootias resultando em relevantes prejuízos econômicos para este setor de atividade [2].

Há relatos de isolamento do microrganismo a partir de alimentos cárneos e surtos de diarréia em humanos [7]. Embora esse microrganismo tenha sido isolado numa freqüência considerada baixa, quando comparado com os demais, essa incidência possivelmente reflete as condições microbiológicas do habitat dos mexilhões analisados. Entretanto, sua importância deve ser reconhecida devido à elevada capacidade de virulência [6].

Foi observada uma freqüência significativa de cepas bacterianas não classificáveis, através da metodologia clássica baseada na capacidade metabólica e bioquímica deste microrganismo. Este episódio ocorreu em $7,36 \%$ das cepas isoladas. Deste percentual, 18 foram isoladas dos mexilhões in natura e 10 cepas dos mexilhões pré-cozidos. Este fato mostra a dificuldade, sob o ponto de vista taxonômico, da identificação deste gênero onde a definição das espécies ainda encontra-se em fase de estabelecimento por Grupo de Trabalho Taxonômico estabelecido pelo Comitê Internacional de Sistemática Bacteriológica [3].

Com relação à sazonalidade dos microrganismos isolados foi possivel observar que algumas espécies tiveram um pico de isolamento no período entre agosto e outubro e outras, como Plesiomonas shigelloides, esporadicamente em diversos períodos do ano. Esses dados sugerem a existência de características sazonais no isolamento de microrganismos dos gêneros Aeromonas e $P$. shigelloides. No entanto, investigações mais apuradas devem ser realizadas para avaliar com maior segurança este tipo de comportamento, pois os resultados podem ser úteis tanto para vigilância ambiental e sanitária quanto epidemiológica [15].

O efeito da temperatura de pré-cozimento dos mexilhões revelou-se em alguns casos efetivo, levando à diminuição de algumas espécies patogênicas como $A$ hydrophila, A. sobria, A veronii biogrupo veronii e $A$. trota. Isso significa que o processo tecnológico de pré-cocção permitiu diminuir a carga microbiana inicial presente no alimento. Esse procedimento tende a minimizar os riscos da contaminação do produto que logo em seguida à pré-cocção será beneficiado, congelado e mantido em temperatura inferior a $-18^{\circ} \mathrm{C}$.

Por outro lado, chama atenção o fato que algumas espécies como A. media, A.caviae, A.jandaei, A. schubertii e $P$. shigelloides foram mais isoladas a partir das amostras pré-cozidas. Estes resultados sugerem que há possibilidade de problemas referentes à manutenção do binômio tempo/temperatura durante a fase de pré-cozimento, ou talvez recontaminação do produto após esta fase. Portanto, a etapa de pré-cozimento deverá ser bem realizada a fim de reduzir a carga microbiana dos mexilhões in natura. A adoção de Boas Práticas de Manufatura pode auxiliar na diminuição da ocorrência de contaminação cruzada ou recontaminação dos mexilhões pré-cozidos [7].

\section{4 - CONCLUSÕES}

A análise microbiológica dos mexilhões in natura e pré-cozidos revelou a alta incidência de microrganismos do gênero Aeromonas, o que constitui sérios riscos para o homem, pois estas bactérias estão associadas ao surgimento de gastrenterites sob a forma de surtos e também outras infecções extraintestinais. Portanto, assinala-se a necessidade urgente de adoção de medidas corretivas e preventivas nos campos das Vigilâncias Sanitária e Epidemiológica. Essas medidas, se adotadas em conjunto, podem auxiliar no aumento da qualidade dos mexilhões oferecidos ao mercado consumidor, bem como na diminuição dos riscos de ocorrência de Doenças de Transmissão Alimentar veiculadas, particularmente por alimentos de origem marinha.

\section{5 - REFERÊNCIAS BIBLIOGRÁFICAS}

[1] ACHA, P.N.; SZYFRES, B. Zoonosis y enfermedades transmissibles comunes al hombre y a los animales. Aeromoniasis. Organizacion Panamericana de la Salud Publica,v. 580, p. 7-13, 2001.

[2] ALVES, D.C.C., Caracterização de Vibrio e Aeromonas em peixes comercializados em feiras livres, no município do Rio de Janeiro. Rio de Janeiro, 2000, 151p. Dissertação (Mestre em Medicina Veterinária), Universidade Federal Rural do Rio de Janeiro (UFRRJ).

[3] COLlins, M.D.; MARTINEZ-MURCIA, A.J.; CAI, J. Aeromonas enteropelogenes and Aeromonas ichthiosmia are identical to Aeromonas trota and Aeromonas veronii respectively, as revealed by samall subunit rRNA sequence analysis. International Journal of Systematic Bacteriology, v. 43, p. 855-856, 1994.

[4] FDA (FOOD AND DRUG ADMINISTRATION), 1992. Bacteriologycal Analytical Manual. 7.ed., 529p.

[5] ICMSF, APCC na qualidade e segurança microbiológica de alimentos. Comissão Internacional para Especificações Microbiológicas dos Alimentos, São Paulo: Varela, 1997.

[6] JANDA, J.M. Recent advances in the study of taxonomy, pathogenicity, and infectious syndromes associated with the genus Aeromonas. Clinical Microbiology Review, v. 4, p. 397-410, 1991. 
[7] KIROV, S.M.; ARDESTANI, E.K.; HAYWARD, L.J. The growth and expression of virulence factors at refrigeration temperature by Aeromonas strains isolated from foods. International Journal of Food Microbiology, v. 20, p. 159-68, 1993.

[8] LEITÃO, M.F. de F.; SILVEIRA, N.F. de A. Aeromonas spp. e Plesiomonas shigelloides na água, pescado e hortaliças no estado de São Paulo. Coletânea do Instituto de Tecnologia de Alimentos, v. 21, p. 90-99, 1991.

[9] MANUAL DE BERGEY. Manual of Determinative Bacteriology, Baltimore: Williams \& Wilkins, 9ed., 1994

[10] MONTEIL, H.; MONTEIL, C.H. Les infections a Aeromonas. La Presse Medicale, v. 26, p. 1790-98, 1997.

[11] NEVES, M.S.; FREITAS, A.C.; NUNES, M.P.; RICCIARDI, I.D. Incidence of motile Aeromonas species in aquatic environments of Rio de Janeiro, Brazil. Journal of Food Protection, v. 55, p. 728-30, 1992.

[12] PEDROSO, D.M.M.; IARIA, S.T.; CERQUEIRA-CAMPOS, M.L.; HELDTMANN, S.; RALL, V.L.M.; PIMENTA, F.;
SAAD, S.M.I. Virulence factors in motile Aeromonas spp. isolated from vegetables. Revista de Microbiologia, v. 28, p. 49-54, 1997.

[13] RALL, V.L.M.; IARIA, S.T.; HEIDTMANN, S.; PIMENTA, F.C.; GAMBA, R.C.; PEDROSO, D.M.M. Aeromonas species isolated from Pintado fish (Pseudoplatystoma sp.): virulence factors and drug susceptibility. Revista de Microbiologia, v. 29, p. 222-27, 1998.

[14] RODRIGUES, D.P.; RIBEIRO, R.V.; HOFER, E. Enterobactérias patogênicas no solo de áreas de recreação da cidade do Rio de Janeiro, RJ. Revista Brasileira de Medicina Veterinária, v. 16, p. 256-59, 1994.

[15] WEST, P.A. The human pathogenic vibrios - A public health update with environmental perspectives. Epidemiology and Infection, v. 103, p. 1-34, 1989.

[16] YAMADA, S.; MATSUSHITA, S.; DEJSIRILERT, S.; $\mathrm{KUDOH}, \mathrm{Y}$. Incidence and clinical symptoms of Aeromonas associated traveller's diarrhoea in Tokyo. Epidemiology and Infection, v. 119, p. 121-26, 1997. 